\title{
TERATOGENICITY TESTING OF SIDDHA FORMULATION OF NILAVEMBU KUDINEER ON ZEBRAFISH (DANIO RERIO) EMBRYO
}

\author{
SHANMUGAPRIYA $\mathbf{P}^{1}$, ELANSEKARAN $\mathrm{S}^{2}$, RAMAMURTHY ${ }^{2}{ }^{2}$, JEEVA GLADYS $\mathbf{R}^{3}$, SIVARAMAN $\mathrm{D}^{4}$, CHRISTIAN GJ $^{2 *}$ \\ ${ }^{1}$ Department of Nanju Maruthuvam, National Institute of Siddha, Chennai, Tamil Nadu, India. ${ }^{2}$ Department of Noi Naadal, National \\ Institute of Siddha, Chennai, Tamil Nadu, India. ${ }^{3}$ Department of Research Methodology and Medical Statistics, Velumailu Siddha Medical \\ College, Sriperumbudur, Tamil Nadu, India. ${ }^{4}$ Centre for Laboratory Animal Technology and Research, Sathyabama Institute of Science and \\ Technology, Chennai, Tamil Nadu, India. Email: christianvijila@gmail.com
}

Received: 18 April 2019, Revised and Accepted:09 July 2019

\section{ABSTRACT}

Objective: The aim of the study was to evaluate the teratogenic effect of Nilavembu Kudineer (NVK) by testing in zebrafish embryo (Danio rerio).

Methods: The study consisted of 30 embryos/culture plate/dose concentration containing a series of diluted decoction of NVK ranging from $10 \mu \mathrm{g}$ to $640 \mu \mathrm{g} / \mathrm{ml}$, and the embryo development was monitored at specific time points. The parameters such as developmental abnormality and adverse events were monitored at 24 hourly intervals for $96 \mathrm{~h}$

Results: The study results showed $100 \%$ hatching and survival of embryos with no significant abnormalities in the extension of study from 96 to $120 \mathrm{~h}$ post-fertilization examinations.

Conclusion: NVK did not have teratogenic potential on testing it in various concentrations on zebrafish embryos validating its safety during pregnancy.

Keywords: Nilavembu kudineer, Dengue, Herbal medicine, Pregnancy, Teratogenicity.

(C) 2019 The Authors. Published by Innovare Academic Sciences Pvt Ltd. This is an open access article under the CC BY license (http://creativecommons. org/licenses/by/4. 0/) DOI: http://dx.doi.org/10.22159/ajpcr.2019.v12i8.33664

\section{INTRODUCTION}

Dengue infection can affect both sexes including pregnant women [1,2]. Recently, there has been a rapid increase in the incidence of dengue infections in adolescents and adults. This included the pregnant women who have been infected with dengue $[3,4]$. Several studies including a retrospective cohort study in French Guiana had calculated the risk of symptomatic dengue infection in pregnancy $[5,6]$. These studies concluded that dengue infection during pregnancy causes poor birth outcomes of pre-term birth and low birth weight that are associated with increased infant morbidity and mortality [7-10].

In spite of advances in molecular and structural virology, no specific antiviral drug has been developed to date due to the critical structural morphology of the dengue virus with several nonstructural proteins. In recent times, any therapeutic lead from herbal origin grabs a higher level of attention due to its versatile modes of action and a wide margin of safety. Siddha drug Nilavembu kudineer (NVK) has been used for treating dengue infections for several years, but till now, there is no proper documentary evidence available with respect to the safety profile of the drug. Hence, the present study aimed at evaluating the safety of the drug NVK using zebrafish embryo toxicity assay. Further, the present study attempted to document the safety of NVK, especially in pregnancy to address the research questions but also the queries from a public health perspective at times of pressing necessity. Furthermore, thorough pregnancy safety profiling of the drug NVK that is said to combat the dengue infection would be necessary for good compliance and confident administration of NVK which could be lifesaving both for the mother and the fetus [11]. In the clinical practice of Siddha Medicine, NVK, which is a polyherbal drug concoction mentioned in classical Siddha text, is being used as the first line of therapy and a general remedy for some types of fever caused by unidentified microbial infections [12]. In this scenario, an attempt has been made in the National Institute of Siddha, Chennai, in subjecting the NVK for screening against teratogenic potential if any to validate its safety during pregnancy and to strengthen the level of evidence given the widespread use of NVK by Siddha practitioners.

\section{METHODS}

\section{Study drug and stock solution}

The ingredients of NVK consisted of nine shade-dried herbs such as Nilavembu (Andrographis paniculata), Vetiver (Vetiveria zizanioides), Vilamichai Ver (Plectranthus vettiveroides), Cantanam (Santalum album), Peyputtal (Trichosanthes cucumerina), Koraikkilanku (Cyperus rotundus), Cukku (Zingiber officinale), Milaku (Piper nigrum), and Parpatakam (Mollugo cerviana) in equal ratio as per the literature Siddha Vaidhya Thirattu which is a scheduled classical text in the Drugs and Cosmetics Act of India. The manufactured drug formulation of NVK was procured from GMP-certified Arogya Healthcare Pvt. Ltd. Chennai. $25 \mathrm{~g}$ of coarse NVK powder with $800 \mathrm{ml}$ of water was used to prepare the aqueous extract by boiling down to become $125 \mathrm{ml}$, and a stock solution of $50 \mathrm{mg} / \mathrm{ml}$ concentration was prepared to be used (Fig. 1)

\section{Selection of species}

Healthy male and female zebrafish continually monitored for two successive generations have been used for breeding to collect the embryos for the present investigation. Fish were free from malformation, signs of infections, and other illnesses.

\section{Ethical consideration}

It is to declare that there is no need for ethical approval for the study involving zebrafish embryos up to 120 hours post-fertilization (HPF). In the present study, observation proceeded with 96 HPF which is $<120$ HPF. Further, no human subjects have been involved in this investigation, and hence, Institutional Ethics Committee approval was not considered mandatory for this study. 
Embryo stock and dosing of the test drug

Sterilized E3 medium was utilized for the maintenance of liver embryos. $8 \mathrm{ml}$ of the sterilized medium was dissolved to $1 \mathrm{~L}$ to get $\times 1$ stock with the inclusion of $100 \mu \mathrm{L}$ of $1 \%$ methylene blue used as a fungicide. Semistatic renewal test was used which is a test with the regular renewal of the test solutions after defined periods (e.g., every 24 h). Everyday fresh medium had been added to the plates containing an embryo. The desired concentration of the test drug was added to the respective plates classified according to the strength.

\section{Methodology}

Toxicity test was based on the OECD guideline No. 236: Fish Embryo Acute Toxicity Test. Fertilized embryos were subjected to the surface sanitation and were transferred into culture plates (30 embryos/ plate/dose concentration) containing a series of diluted decoction of NVK ranging from $10 \mu \mathrm{g}$ to $640 / \mathrm{ml}$. Distilled deionized water was used as control exposure involved semi-static renewal condition, $25 \pm 1^{\circ} \mathrm{C}$ and 14 light: 10 dark cycle period. Plates were sealed to minimize evaporation. Embryo development was monitored in 24-h intervals for $96 \mathrm{~h}$, and the test parameters were evaluated using inverted microscope

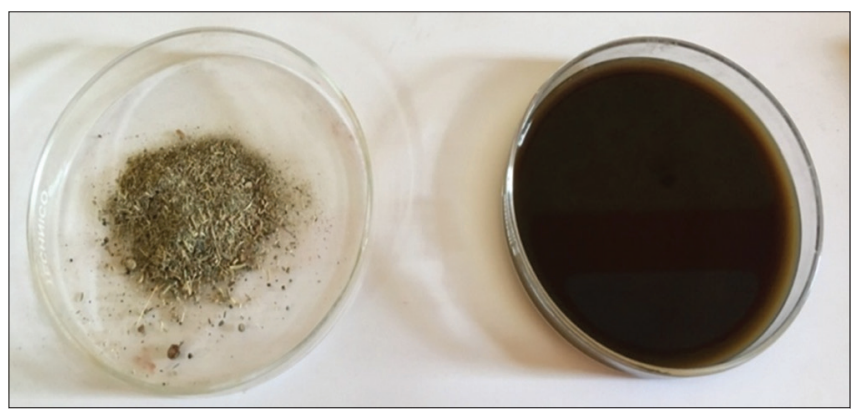

Fig. 1: Photograph of crude and extracted drug Nilavembu kudineer equipped with phase-contrast function, camera, and software for image optimization. Mortalities, if any, were looked for at 24, 48, 72, and 96 HPF [13].

\section{RESULTS}

NVK is a classical polyherbal Siddha formulation that is indicated in Siddha literature as a broad spectrum pharmacotherapeutic agent in the management of fevers.

During the recent outbreaks of dengue in Tamil Nadu and Kerala, South India, Siddha physicians rose to the occasion and managed the condition well with NVK, drawing parallel the signs and symptoms of dengue fever with that of "Pitha Suram" as classified by Sage Yugi. This initiative received great patron from the Tamil Nadu State government. Of late, there has been an overwhelming use of NVK, particularly in pregnancy, spurred by the maternal and fetal deaths reportedly due to dengue that warrants the need to establish the safety of NVK during gestation. The results in Table 1 represent the parameters observed in zebrafish for embryotoxicity to identify the developmental abnormalities if any. Table 2 represents the statistical analysis on embryo movement at $24 \mathrm{HPF}$ and heartbeat at $48 \mathrm{HPF}$ in 30 embryos/culture plate/ dose concentration containing a series of diluted decoction of NVK ranging from $10 \mu \mathrm{g}$ to $640 \mu \mathrm{g} / \mathrm{ml}$. Fig. 2 portrays the photographs of teratogenicity testing of NVK in zebrafish embryo up to $96 \mathrm{HPF}$.

Table 1 represents the observation of various abnormalities and vital parameters in zebrafish embryo in the control group: $10 \mathrm{mcg}$ of NVK; 20 mcg of NVK; 40 mcg of NVK; 80 mcg of NVK; 160 mcg of NVK; 320 mcg of NVK; and 640 mcg of NVK. *NO - None observed, N - Normal, AN Appears normal, NSA - No such abnormality was observed.

Table 2 represents the mean, standard deviation (SD), and standard error (SE) of zebrafish embryo movement at $24 \mathrm{HPF}$ and heartbeat at $48 \mathrm{HPF}$ in control group $10 \mathrm{mcg}$ of NVK; $20 \mathrm{mcg}$ of NVK; $40 \mathrm{mcg}$ of NVK; $80 \mathrm{mcg}$ of NVK; $160 \mathrm{mcg}$ of NVK; $320 \mathrm{mcg}$ of NVK, and $640 \mathrm{mcg}$ of NVK.

Table 1: Observed parameters in zebrafish embryotoxicity study

\begin{tabular}{|c|c|c|c|c|c|c|c|}
\hline \multirow[t]{2}{*}{ Parameters } & \multicolumn{7}{|c|}{ Concentration $(\mu \mathrm{g})$} \\
\hline & 10 & 20 & 40 & 80 & 160 & 320 & 640 \\
\hline Developmental abnormality & NO & NO & NO & NO & NO & NO & NO \\
\hline Loss of equilibrium & NO & NO & NO & NO & NO & NO & NO \\
\hline Pigmentation & $\mathrm{N}$ & $\mathrm{N}$ & $\mathrm{N}$ & $\mathrm{N}$ & $\mathrm{N}$ & $\mathrm{N}$ & $\mathrm{N}$ \\
\hline Abdominal distension & NO & NO & NO & NO & NO & NO & NO \\
\hline Melanophores migration from neural crest & AN & AN & AN & AN & AN & AN & AN \\
\hline Puffy & NSA & NSA & NSA & NSA & NSA & NSA & NSA \\
\hline Bent tails/body axes & NO & NO & NO & NO & NO & NO & NO \\
\hline Pericardial edema & NSA & NSA & NSA & NSA & NSA & NSA & NSA \\
\hline Peritoneal edema & NSA & NSA & NSA & NSA & NSA & NSA & NSA \\
\hline Percentage survival & $100 \%$ & $100 \%$ & $100 \%$ & $100 \%$ & $100 \%$ & $100 \%$ & $100 \%$ \\
\hline Hatching rate & $100 \%$ & $100 \%$ & $100 \%$ & $100 \%$ & $100 \%$ & $100 \%$ & $100 \%$ \\
\hline Heartbeat & $\mathrm{N}$ & $\mathrm{N}$ & $\mathrm{N}$ & $\mathrm{N}$ & $\mathrm{N}$ & $\mathrm{N}$ & $\mathrm{N}$ \\
\hline Yolk-sac edema & NSA & NSA & NSA & NSA & NSA & NSA & NSA \\
\hline Hyperpigmentation & NO & NO & NO & NO & NO & NO & NO \\
\hline Pectoral fin malformation & NO & NO & NO & NO & NO & NO & NO \\
\hline Trunk axis & AN & AN & AN & AN & AN & AN & AN \\
\hline Spontaneous movement & $\mathrm{N}$ & $\mathrm{N}$ & $\mathrm{N}$ & $\mathrm{N}$ & $\mathrm{N}$ & $\mathrm{N}$ & $\mathrm{N}$ \\
\hline Heart formation & $\mathrm{N}$ & $\mathrm{N}$ & $\mathrm{N}$ & $\mathrm{N}$ & $\mathrm{N}$ & $\mathrm{N}$ & $\mathrm{N}$ \\
\hline Curved or bent axis & NO & NO & NO & NO & NO & NO & NO \\
\hline Eye malformation & NO & NO & NO & NO & NO & NO & NO \\
\hline Blood circulation & $\mathrm{N}$ & $\mathrm{N}$ & $\mathrm{N}$ & $\mathrm{N}$ & $\mathrm{N}$ & $\mathrm{N}$ & $\mathrm{N}$ \\
\hline Mortality & $0 \%$ & $0 \%$ & $0 \%$ & $0 \%$ & $0 \%$ & $0 \%$ & $0 \%$ \\
\hline Arrested growth & NO & NO & NO & NO & NO & NO & NO \\
\hline Craniofacial malformations & NO & NO & NO & NO & NO & NO & NO \\
\hline Peripheral ischemia and disruption of erythropoiesis & NO & NO & NO & NO & NO & NO & NO \\
\hline Accumulation of fluid around the heart & NO & NO & NO & NO & NO & NO & NO \\
\hline Response to stimuli & $\mathrm{N}$ & $\mathrm{N}$ & $\mathrm{N}$ & $\mathrm{N}$ & $\mathrm{N}$ & $\mathrm{N}$ & $\mathrm{N}$ \\
\hline Coagulation of eggs & NO & NO & NO & NO & NO & NO & NO \\
\hline Tail detachment & NO & NO & NO & NO & NO & NO & NO \\
\hline
\end{tabular}

*NO: None observed, N: Normal, AN: Appears normal, NSA: No such abnormality 
Table 2: Statistical analysis on embryo movement at $24 \mathrm{HPF}$ and heartbeat at $48 \mathrm{HPF}$

\begin{tabular}{|c|c|c|c|c|c|c|c|}
\hline \multirow[t]{2}{*}{ Parameters $\mathrm{N}=\mathbf{3 0}$} & \multicolumn{7}{|c|}{ Concentration $(\mu \mathrm{g})$} \\
\hline & 10 & 20 & 40 & 80 & 160 & 320 & 640 \\
\hline \multicolumn{8}{|l|}{ Embryo movement at $24 \mathrm{HPF}$} \\
\hline Mean & 7.833 & 7.333 & 8.067 & 7.5 & 7.433 & 7.533 & 7.567 \\
\hline Standard deviation (SD) & 0.8743 & 0.8442 & 0.5833 & 0.6297 & 1.406 & 1.042 & 0.9714 \\
\hline Standard error (SE) & 0.1596 & 0.1541 & 0.1065 & 0.115 & 0.2568 & 0.1902 & 0.1774 \\
\hline \multicolumn{8}{|l|}{ Heartbeats/Min at $48 \mathrm{HPF}$} \\
\hline Mean & 124.9 & 125 & 123.9 & 126 & 124.4 & 125.1 & 124.4 \\
\hline Standard deviation (SD) & 2.924 & 2.6 & 2.369 & 2.47 & 2.442 & 2.638 & 2.725 \\
\hline Standard error (SE) & 0.5338 & 0.4746 & 0.4324 & 0.451 & 0.4459 & 0.4817 & 0.4975 \\
\hline
\end{tabular}

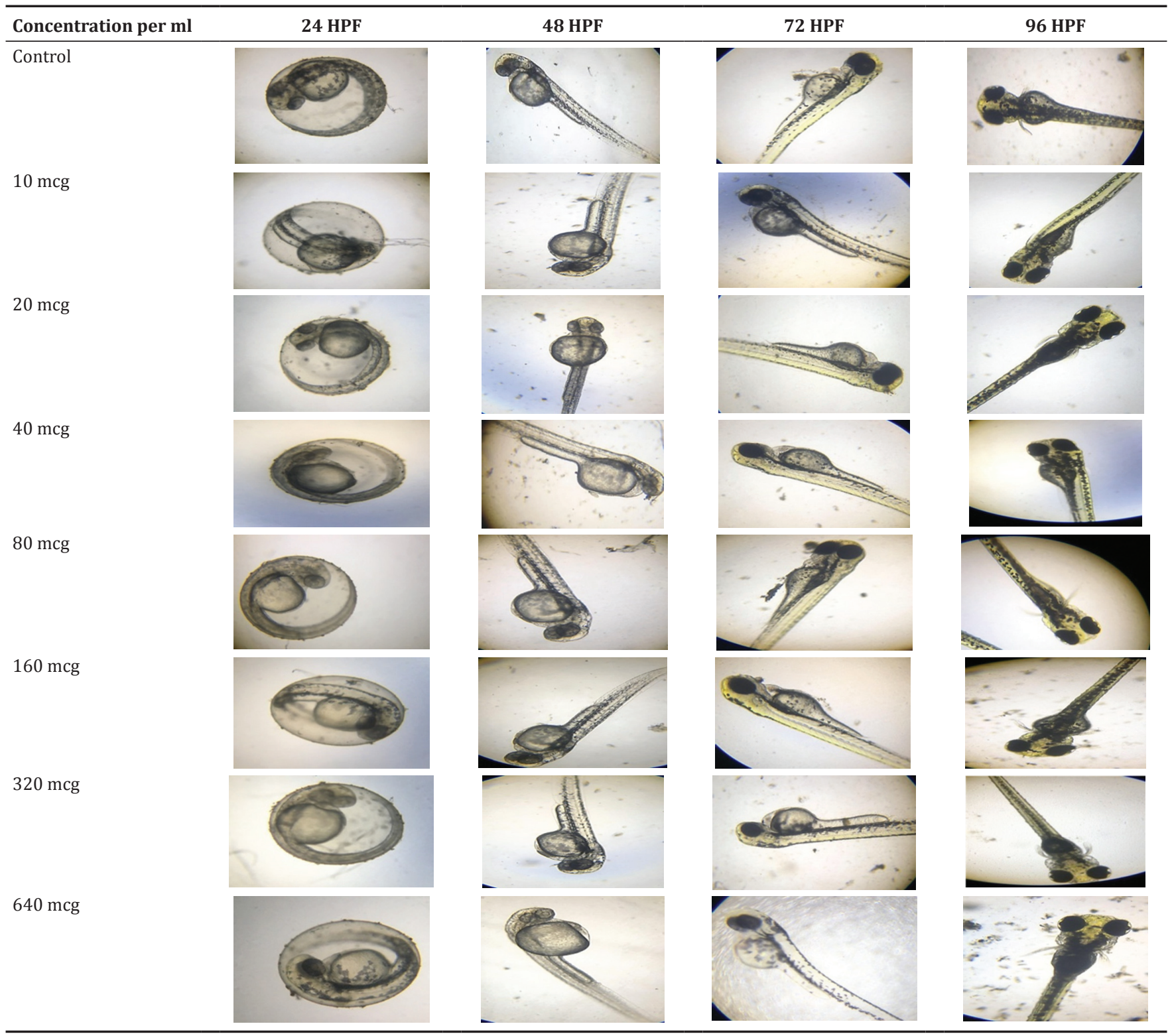

Fig. 2: Teratogenicity testing of NVK in zebrafish embryo

Fig. 2 Represents the images of zebra fish embryos in the control group; $10 \mathrm{mcg}$ of NVK; $20 \mathrm{mcg}$ of NVK ; $40 \mathrm{mcg}$ of NVK; $80 \mathrm{mcg}$ of NVK;160 mcg of NVK; 320 mcg of NVK; 640 mcg of NVK observed at different time points $(24,48$ and $72 \mathrm{HPF})$. There were hatched larvae at $48 \mathrm{HPF}$. No developmental abnormalities such as cardiac edema, notochord malformation, tail hyperplasia, yolk sac deformity, and growth retardation were noted up to $96 \mathrm{HPF}$

\section{DISCUSSION}

The organoleptic evaluation of NVK decoction has been shown to be strongly aromatic, greenish-brown liquid, and the extract was highly soluble in water; sparingly soluble in methanol and dimethyl sulfoxide; and insoluble in ethanol, n-hexane, and chloroform. Although this classical formulation has been used for thousands of years, for 
the treatment of various types of fevers still there is no scientific data regarding its safety during pregnancy [14]. At present, the emerging challenges and controversies regarding the safe use of this formulation in pregnancy have instigated the investigators to conduct this research in zebrafish (Danio rerio) embryo. Zebrafish species has been validated as a biomedical relevant model for functional genomics and in vivo drug discovery [15], identification of therapeutic potential of bioactive natural products, and testing of teratogenicity because of their high genetic, physiological, and pharmacological similarity to humans.

Moreover, the small size of embryos and larvae, the high fecundity of adult zebrafish as it produces hundreds of offspring per breeding pair per week, easy visualization of internal organs and tissues due to optical transparency of embryos, and the speed at which these develop ex utero are the primary advantages of zebrafish as a model organism for teratogenicity testing [16]. The embryogenesis of zebrafish is very rapid, with the entire body plan established by $24 \mathrm{HPF}$. Moreover, most of the internal organs including heart, liver, intestine, and kidney are fully developed by 96 HPF [17]. Although NVK is a time-tested formulation and no adverse effects have been reported clinically, no study has been performed to check the teratogenicity so far as per our search and there is scarce scientific knowledge regarding its safety during pregnancy in approved pharmacological models. In this study, our main objective was to study the developmental effects of NVK on zebrafish embryos.

In the teratogenicity testing of zebrafish embryo, the mortality, hatchability, heartbeat, and malformations were recorded. Mortality endpoints were defined as coagulated embryos with no visual heartbeat. Teratogenicity endpoint was determined as malformed head, tail and heart, scoliosis, deformity of yolk, and growth retardation. Heartbeat is an important parameter in determining the physiological effects of NVK [18]. The study results revealed that both the tested embryos and the control embryos in the medium significantly established very distinct pigmentation on both head and tail regions, pigmented retina of the eyes, narrowing of the yolk, and strong circulation characterized by visible heartbeat etc., at the concentration ranging from $10 \mu \mathrm{g}$ to $640 \mu \mathrm{g} / \mathrm{ml}$ and were documented at specific time points $(\mathrm{t}=24,48,72$, and $96 \mathrm{HPF})$.

Hatching is suggestive of the successful developmental processes of the embryos [18]. Hatching was completed at 48 HPF in both tested and control embryos, and there was $100 \%$ hatchability of embryos treated with the different concentrations of NVK extracts. Therefore, the results advocate that there is no retarded growth in the NVK-exposed embryos. Further, the test drug did not cause any mortality even in higher concentrations resulting in $100 \%$ survival with no developmental abnormality in the tested embryos (Fig. 2). NVK did not alter the heart rate and normal morphology of the developing embryos. There were no signs of an adverse event such as edema, axial formation, and melanophore migration and no significant change was observed during the extension of study from 96 to 120 HPF examinations (Table 1).

The mean embryo movement at $24 \mathrm{HPF}$ and heartbeat at 48 HPF were statistically analyzed for its mean, SD, and SE at the concentrations ranging from $10 \mu \mathrm{g}$ to $640 \mu \mathrm{g} / \mathrm{ml}$, and there was no significant change among all the tested concentrations as shown in Table 2.

Teratogenicity testing on acetaminophen or paracetamol which is a general conventional analgesic and antipyretic used by all groups of people including pregnant women has been found to induce anomalies when tested in zebrafish embryo causing impairment in hatching, early development, organogenesis, larval growth, tail and fin formation, pigmentation, larval behavior, and survival [19]. Furthermore, acetylsalicylic acid (aspirin), which is a nonsteroidal anti-inflammatory drug with analgesic, antipyretic, and anti-inflammatory effects, seems to be associated with a higher incidence of malformations in fish embryos [20]. In another study, embryotoxicity of diclofenac on zebrafish embryos was studied at 12 HPF and was treated with different dosages of diclofenac (0-2000) at specific time points (12-72 HPF). The results revealed that higher doses ( 5 and $10 \mathrm{ppm}$ ) of diclofenac exposure resulted in defective phenotypes including malformed somites, twisted body axis, and shorter body length, suggestive of disturbance in actin organization and muscle fiber alignment [21].

While the teratogenicity testing of conventional antipyretics and analgesics in zebrafish embryos has proved them to be unsafe during pregnancy, the present study of NVK on the zebrafish embryo model provided data showing clear gestational safety margin of NVK that could be extrapolated for use in pregnant women suffering from fevers including dengue. Furthermore, previous acute toxicity studies on NVK by Anbarasu et al. (2011) revealed that the ethanolic extract of NVK did not show mortality and toxic signs up to $2000 \mathrm{mg} / \mathrm{kg}$ and supports its indication for various fevers such as dengue and chikungunya fever as it had antipyretic, anti-inflammatory, and analgesic activity in experimental mice models [22]. Furthermore, there were no adverse effects reported in the earlier clinical studies on NVK administration both in adults [23] and pediatric population [24-26]. Thus, the present study results are found to be in concordance with the in vivo animal and human data of previous studies.

\section{CONCLUSION}

The study of polyherbal Siddha formulation of NVK on the zebrafish embryo model for teratogenicity according to the OECD 236 guidelines did not produce any evidence of reproductive toxicity in all the observed parameters such as mortality, hatchability, heartbeat, and malformations that are sensitive indicators of teratogenicity. Throughout the administration of $10-640 \mu \mathrm{g} / \mathrm{ml}$ serial concentrations of NVK to the embryo culture monitored at $24 \mathrm{~h}$ intervals up to $96 \mathrm{HPF}$, no significant change was observed. Moreover, even when they were observed in the extension of study from 96 to $120 \mathrm{HPF}$ examinations, no abnormality or embryo defect was detected. Thus, the Siddha polyherbal formulation of NVK has been scientifically tested for teratogenicity and consequently validated for its safety during pregnancy.

\section{ACKNOWLEDGMENT}

The author wishes to acknowledge the contribution of Postgraduate Scholars, Department of Noi Naadal, and Prof. Dr. N. J. Muthukumar, Director of National Institute of Siddha, Chennai, for their extended support in conducting this research work.

\section{AUTHORS' CONTRIBUTIONS}

The authors, Dr. P. Shanmugapriya, Dr. S. Elansekaran, and Dr. M. Ramamurthy being Siddha physicians, were involved in the identification, characterization, and formulation of the NVK. The authors, Dr. D. Sivaraman and Dr. Jeeva Gladys, were involved in the development of the study protocol and execution of the study in a wet laboratory. All the authors have equally contributed in preparing this manuscript.

\section{CONFLICTS OF INTEREST}

Authors declare no conflicts of interest in the present study

\section{REFERENCES}

1. Rajalakshmi P, Lavanya R, Brindha P. Process standardization studies on ganthaga rasayanam. Int J Pharm Pharm Sci 2012;4:118-28.

2. Guzman MG, Halstead SB, Artsob H, Buchy P, Farrar J, Gubler DJ, et al. Dengue: A continuing global threat. Nat Rev Microbiol 2010;8:S7-16.

3. Bhatt S, Gething PW, Brady OJ, Messina JP, Farlow AW, Moyes CL, et al. The global distribution and burden of dengue. Nature 2013;496:504-7.

4. Goh KT. Changing epidemiology of dengue in Singapore. Lancet 1995;346:1098.

5. Guha-Sapir D, Schimmer B. Dengue fever: New paradigms for a changing epidemiology. Emerg Themes Epidemiol 2005;2:1.

6. Kariyawasam S, Senanayake H. Dengue infections during pregnancy: Case series from a tertiary care hospital in Sri Lanka. J Infect Dev 
Ctries 2010;4:767-75

7. Fernández R, Rodríguez T, Borbonet F, Vázquez S, Guzmán MG, Kouri G, et al. Study of the relationship dengue-pregnancy in a group of cuban-mothers. Rev Cubana Med Trop 1994;46:76-8.

8. Christiaens I, Zaragoza DB, Guilbert L, Robertson SA, Mitchell BF, Olson DM, et al. Inflammatory processes in preterm and term parturition. J Reprod Immunol 2008;79:50-7.

9. Howson CP, Kinney MV, Lawn JE, editors. March of Dimes, PMNCH, Save the Children, Born Too Soon: The Global Action Report on Preterm Birth. Geneva; World Health Organization: 2012.

10. Pouliot SH, Xiong X, Harville E, Paz-Soldan V, Tomashek KM, Breart $\mathrm{G}$, et al. Maternal dengue and pregnancy outcomes: A systematic review. Obstet Gynecol Surv 2010;65:107-18.

11. Carroll ID, Toovey S, Van Gompel A. Dengue fever and pregnancy a review and comment. Travel Med Infect Dis 2007;5:183-8.

12. Noble CG, Shi PY. Structural biology of dengue virus enzymes: Towards rational design of therapeutics. Antiviral Res 2012;96:115-26.

13. Mudaliyar KN, Utthamarayan KS. Thirattu SV. Directorate of Indian Medicine. $3^{\text {rd }}$ ed. Chennai: Homeopathy Press; 2009. p. 294.

14. Organisation for Economic Co-operation and Development Fish Embryo Acute Toxicity (FET) Test Guideline No. 236, (Guidelines For Testing Of Chemicals, Paris; 2013. Available from: https:// www.oecd-ilibrary.org/environment/test-no-236-fish-embryo-acutetoxicitytest_9789264203709-en. [Last accessed on 2019 Jul 05]

15. Sukanda EY, Kurniati NF. Evaluation of teratogenicity effects of ethanolic extractsof binahong leaves (Anredera cordifolia(ten) Steenis) in Wistar rat. Int J Pharm Pharm Sci 2014;6:422-6.

16. Mudaliyar KN. Siddha Maruthuvam Pothu. $7^{\text {th }}$ ed. Chennai: Directorate of Indian Medicine and Homeopathy Press; 2007. p. 20.

17. Zon LI, Peterson RT. In vivo drug discovery in the zebrafish. Nat Rev Drug Discov 2005;4:35-44.

18. Crawford AD, Esguerra CV, de Witte PA. Fishing for drugs from nature:
Zebrafish as a technology platform for natural product discovery. Planta Med 2008;74:624-32.

19. Hozzein WH, Farooq M, Al-Malki AH, Wadena MA, Developmental effects of extracts produced by some newly isolated Actinobacteria on the heart of zebrafish (Danio rerio) embryos. Asian J Pharm pharmacol 2013;7:1680-5.

20. Romagosa CR, Cherry MR, David ES, Milton RR. Embryo-toxic and teratogeniceffects of Tinospora cordifolia leaves and bark extracts in zebrafish (Danio rerio) embryos. Asian J Plant Sci Res 2016;6:37-41.

21. David A, Pancharatna K. Effects of acetaminophen (paracetamol) in the embryonic development of zebrafish, Danio rerio. J Appl Toxicol 2009;29:597-602.

22. Cook JC, Jacobson CF, Gao F, Tassinari MS, Hurtt ME, DeSesso JM, et al. Analysis of the nonsteroidal anti-inflammatory drug literature for potential developmental toxicity in rats and rabbits. Birth Defects Res B Dev Reprod Toxicol 2003;68:5-26.

23. Chen YH, Chang CY, Wang YH, Wen CC, Chen YC, Hu SC, et al. Embryonic exposure to diclofenac disturbs actin organization and leads to myofibril misalignment. Birth Defects Res B Dev Reprod Toxicol 2011;92:139-47.

24. Anbarasu K, Manisenthil KK, Ramachandran S. Antipyretic, antiinflammatory and analgesic properties of nilavembu kudineer choornam: A classical preparation used in the treatment of chikungunya fever. Asian Pac J Trop Med 2011;4:819-23.

25. Christian GJ, Subramanian M, Periyasami D, Manickavasakam K, Gunasekaran P, Sivasubramanian S. Protective effect of polyherbal siddha formulation-nilavembukudineer against common viral fevers including dengue a case-control approach. Int $\mathrm{J}$ Pharm Sci Res 2015;6:1656-60

26. Kalaiarasi R, Jeeva Gladys R, Elangovan S, Soundararjan DK, Mubarak H, Kanakarajan A. A combination of nilavembu kudineer and Adathodai manapagu in the management of dengue fever. Int J Cur Res 2013;5:978-81. 